\title{
RESEARCH ARTICLE \\ Combating the Stress of an Urgent Move to Remote Learning Caused by the COVID Pandemic
}

\author{
Alina M. Zapalska*, Christopher LaMonica, and Stephen Hart \\ U.S. Coast Guard Academy, USA.
}

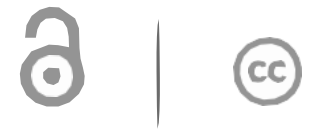

Open Access

Citation: Zapalska, A M., LaMonica, C., \&, Hart, S. Combating the Stress of an Urgent Move to Remote Learning Caused by the COVID Pandemic. Interdisciplinary Education and Psychology. 2020; 2(3):4.

Received: October 22, 2020

Accepted: November 27, 2020

Published: December 31, 2020

Copyright: @2020 Zapalska,AM. This is an open access article distributed under the terms of the Creative Commons Attribution License, which permits unrestricted use, distribution, and reproduction in any medium, provided the original author and source are credited.

\section{Corresponding author:}

Alina M. Zapalska, U.S. Coast Guard Academy, USA; E-mail:

Alina.M.Zapalska@uscga.edu

\begin{abstract}
Remote learning became the primary venue for university education throughout the world during the COVID-19 pandemic. While some academic institutions already had remote learning mechanisms in place by design, many higher education institutions along with faculty and students - had to adapt to virtual or online education for the first time, while school was in session, in spring 2020. The continued effort to improve online pedagogy during the 2020-21 academic year suggests new pedagogical norms are now being established, with longer term implications for educators and students alike. In this paper, the authors explore different technologies used in the "classroom" and observed impacts on teaching effectiveness, particularly as they relate to an undergraduate economics course. The author find that while it is challenging to replicate the in-person class experience, basic economics courses can be effectively taught in a remove environment by leveraging technology.
\end{abstract}

\section{Keywords}

Virtual or online education, technology, computer, teaching, effectiveness

\section{Introduction}

Many higher education institutions have made a commitment to introduce on-line and computing educational technologies to their campuses (Angiello, 2010). The most attractive technological instruments are those that involve improvement in quality of teaching and create learning environments that are flexible, dynamic, and capable of responding to a wide variety of individual needs and learning styles (Fish and Wickersham, 2019). On-line technology like the World Wide Web, WebCT, WebCT Vista, Desire 2 Learn (D2L) and other multimedia authoring tools provide new means for teaching and learning and can provide a level of flexibility and convenience not provided by traditional classroom courses (Burdea and Coiffet, 2004). In particular, remote or distance learning opens educational access to nontraditional and geographically distributed students and can improve the overall educational process by reducing time, labor, and costs (Beck, 2019).

As COVID-19 surges across the United States, educators in colleges and universities in the United States have been challenged to drastically increase the use of virtual or distance delivery of courses, tutoring advising and other student support services. To protect health and community resilience, distance learning has become the only safe and practical choice for many students and institutions during the pandemic. Virtual learning attempts to replicate classroom teaching in an on-line mode and is an increasingly prominent form of distance education. As the number of distance-learning programs has increased and the range of delivery techniques have grown, especially during the COVID-19 pandemic, it is imperative to examine the use and the effectiveness of distance education methodologies and technologies in order to select and deploy the best alternatives.

The primary goal of this article is to offer reflections on various aspects of the design of economics courses in a remote environment during the COVID-19 pandemic. We find that specially designed platforms such as D2L, and Microsoft Teams work to bridge the gap between the textbook and other learning resources, leading to improved quality of the students' learning outcomes. 
These platforms can successfully simulate face-to-face-teaching models and contribute to the time and cost-effectiveness of course development. To be successful, however, virtual education requires adjustments in certain areas such as faculty and student training, specific course organization, and hands-on work to ensure students are engaged in a course.

We provide examples of effective technologies and pedagogical strategies for distance education that were developed especially for distance education during the COVID-19 pandemic within a small Management Program at the United States Coast Guard Academy (USCGA). The article concludes that the increasing dependency of college education on distance or virtual instruction seems inevitable. We conclude that remote coursework must be based on an instructor's effectiveness at creating a course design that meets the needs of students for greater engagement in course instruction and greater relevance of the subject matter to an increasingly more global, competitive, and challenging business world. The article provides a framework for how effective distance education can be delivered by focusing on learning resources, pedagogy, learner support and management.

\section{Literature Review}

In recent years, numerous studies have argued that the effectiveness of education increases if instruction is routinely reexamined, allowing for the mix of teaching methods to change over time. Many authors believe that the use of new technologies facilitates the ability of faculty to address teaching and learning issues (Beck, 2019; Angelino, and Natvig, 2010). Computer technology-based instruction can be used to enhance the quality of learning by enabling students to take new and more active roles in the learning process and making a great array of resources available to students for use both inside and outside the classroom. Computer technology-based instruction, especially in remote environments, has the freedom to move outside the classroom environment while a closed system such as a book may be confined to areas pre-determined by the instructor or the author of the book.

Computer technology-based instruction also provides increased opportunities for interaction between and among students and can create experiences that promote the development of higher-order cognitive skills rather than the simple transfer of content (Guthrie, and McCracken, 2010). Materials can be designed to address the various students' learning styles by incorporating a variety of multimedia elements, such as text, graphics, audio, video and animation, chats, and discussion boards. Moreover, computer technology instruction provides support, feedback, and guidance through both synchronous and asynchronous communications (Valsamidisa et al., 2017).

The rapid access to resources can promote higher levels of student involvement and motivation. Interactive peer reviews from the global educational community can also be a powerful motivating force leading to improved effort and self-esteem of students (Trajkovic et al., 2000). Computer-based technology provides an easy mechanism for electronic publishing where both students and instructors can present their work to a global audience. The posting of students' projects, papers, and other work may be used as the basis for modeling, discussion, or review (Juwah, 2006). Importantly, web-based instruction is accessible but restricted to those who are enrolled and have assigned passwords. This limited accessibility enables both students and instructors to send and receive homework, assignments, reports, and exams confidentially.

Computer technology-based instruction can be employed to promote experiential learning or learning "on site" so that the educational process is integrated into the real world. Kearsley (2000) argues that web-based resources are easily available and provide a variety of materials so that learning becomes more relevant as students browse through libraries, museums, and archives or consult experts from around the globe. While traditional instruction may tend to discourage social interaction, computer technology-based instruction is designed for collaboration and interaction, both of which can be effectively employed in the learning process. This type of social interaction also fosters a greater sense of accountability among the students. The ability of the faculty and students to communicate privately or collectively in a synchronous or asynchronous manner creates a new dimension to the design of instructional strategies.

The rich environment of computer technology together with Web-based resources can (1) promote study and investigation within authentic, realistic, meaningful, relevant, complex, and information-rich contexts; (2) encourage the growth of the student responsibility, 
initiative, decision making, and intentional learning; (3) cultivate an atmosphere of cooperative learning among students and teachers; (4) utilize dynamic, generative learning activities that promote a higher-level thought process (i.e. analysis, synthesis, problem solving, experimentation, and creativity among many others); and (5) easily assist with assessing student progress in learning through realistic tasks and performances.

\section{Ideas Behind the Course (Course Activities)}

During the Spring of 2020, the Management Department at the USCGA moved its traditionally delivered courses into remote or virtual offering due to the COVID-19 pandemic. The Principles of Macroeconomics course had been offered to the freshmen class, and therefore this rapid transition from a traditional classroom environment to remote teaching was very challenging for the students enrolled in this course. This web-enhanced instruction was used to develop a learning environment that facilitated interactive learning with the use of Internet resources and computer-based communication platforms. The course consisted of 78 students. The U.S. Coast Guard Academy provided the technical support needed for students and instructor to efficiently communicate and collaborate throughout a second portion of the course.

Figure 1. Learning Experiences in Online Education.

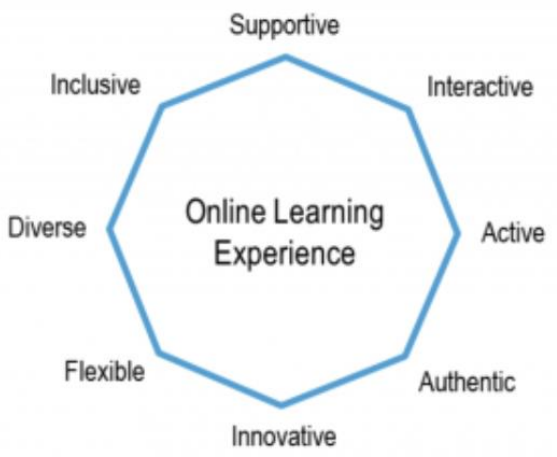

Source: The Management Department, U.S. Coast Guard Academy

Computer technology-based instruction in an economics course was designed to be supportive, interactive, active, authentic, innovative, flexible, diverse, and inclusive. Each category is explained in Table 1.

Table 1. Understanding Learning Experiences in Online Education.

Supportive - using techniques that supported development of specific skills such as critical thinking (via problems solving)

Interactive - working together using for example group assignments or discussions

Active - active learning by doing instead of listening to a lecture

Authentic - using case studies and real data and examples.

Innovative - we used the most current/up-to-date technology available for distance learning

Flexible - deadlines were required but students could progress on their own pace and complete the course before the end of semester.

Diverse - utilizing numerous course materials for teaching and learning

Inclusive - covering all topics and concepts as the course materials was building as students progressed with course.

In order for computer-based teaching in a remote environment to operate efficiently, an adequate technological infrastructure must be provided to serve instructors as well as 
students. The U.S. Coast Guard Academy's Information Technology staff assisted with the adoption of user-friendly hardware and software which provided a platform for course delivery and helped maintain the accuracy, reliability, and security of the system. The rationale for building and developing a web-enhanced course was a lack of up-to-date information in the course textbook. Students were dissatisfied with the low level of interaction with the professor and fellow students necessitated by a large lecture style class. In addition, students wanted a means of assessing their knowledge of the course material before exams. Thus, the goals of the economics course were (1) to augment the textbook and lectures with current information; (2) to provide feedback to students concerning their progress in the course; (3) to improve communication between students and the instructor; (4) to facilitate greater communication between students; (5) to experiment with the technology in order to move the course toward a distance education paradigm; and (6) to use technology to change the course pedagogy to discovery learning.

\section{Pedagogical Approach}

Prior to the COVID-19 pandemic, the course was built into four sections and each section had implemented computer-based technology to enhance the course effectiveness. Originally, course activities included the traditional face-to-face format including lecture, active collaborative learning, discussion, and debates and presentations in a classroom. However, due to the COVID-19 pandemic, the second half of the semester had to be redesigned to adopt all learning into computer-based instruction and to permit more individualized learning and pacing. Enhanced Microsoft Teams and D2L software packages as well other the web-based resources were intensively used during the second half of the course due to circumstances of the pandemic. Computer-based instruction materials and resources offered features that promoted integration of learning strategies where students were able to use multiple tools to support their education. Some of those tools included library-based readings, computer-based quizzes and tests based on multiple-choice and problem questions, Narrated PowerPoint presentations, teacher class materials that were available as pdf documents, and a library of educational videos on various macroeconomics principles.

Effective remote and computer technology-based education requires more deliberate faculty involvement to bridge the gap between remote instruction and face-to-face instruction. In order to stimulate critical thinking, activities were provided throughout the course that included discussions, individualized attention to students who needed additional help, timely and thorough feedback of assignments, and ad-hoc problem-solving assignments. In addition to lectures and assignments, web-based resources and websites of professional and institutional organizations were posted on the D2L page, and new useful links were added to expand students' learning opportunities. The course moved away from individual to group assignments to allow students to work more collaboratively and, in general, to help teach each other.

Students were encouraged to use D2L e-mail, bulletin boards, and the course chat room as well as Microsoft Teams to assist in completing assignments and enhance their learning. It was important to guide students as to what on-line resources, not provided by the instructor or textbook, were reliable, pertinent, and accurate. All the instruction and assistance helped to alleviate anxiety and restlessness caused by the COVID-19 pandemic and the rather sudden move to a remote learning environment. Additionally, multiple modes and methods of instruction were provided to the students to mitigate the lack of a single class period, as the course was taught in an asynchronous fashion.

By using computer-based technology, students were able to share ideas and exchanged information and knowledge with each other while working collaboratively in a remote environment. Students reviewed their lessons and did exercises at their convenience. They received feedback from the exercises quickly so that they knew where they needed to focus while studying. Searching for information was facilitated by using web-based resources as students were able to access them at any time from their home computers. The D2L tool within the course enabled students to review their class materials at any time and discuss them with other students by using bulletin boards, chat rooms, or e-mail. The assignments were submitted over D2L and received responses more quickly.

D2L Platform within the Course 
D2L was used to deliver course materials as well as for the administration of all quizzes and exams. Delivery was developed around the course syllabus. The syllabus did not change after the COVID-19 pandemic, and it stayed the same as the paper syllabus handed out to students at the beginning of the semester. However, the on-line version provided a link to the module for each topic, as well as supplementary materials, such as instructor's lecture notes, PowerPoint presentations and in-class exercises. Each module page included a list of learning objectives, a hyperlink table of contents for subtopics, a button to launch a quiz, and the content material. The purpose of the on-line content was to update the textbook and complement other source for the course. The material also provided links with other academic and commercial sites that had relevant information.

In order to facilitate greater communication, the course D2L platform included a discussion forum (chat room) area. Students were encouraged to use the discussion area, and postings could be counted towards the student's class participation grade. This helped assure that all students would take part in the virtual classroom. Students used the D2L quiz program to assess their knowledge of topics before the actual exam. The quizzes were in a multiplechoice format and were not used in the calculation of students' grades. Ten questions were randomly selected from a database of approximately one hundred questions per topic. Along with the grade for the quiz, each student received corrected answers to all questions and was provided with specific advice concerning mastery of the subject matter. Due to the random selection of questions students could take the quiz a number of times before all questions were viewed, and students were encouraged to retake the quizzes until they had mastered the subject material.

\section{Course Documents}

The course materials covered detailed course information. Students could view a syllabus and a course outline on D2L. All course documents, including the syllabus, lecture notes presented via the PowerPoint presentations, and assignments were accessible via the D2L learning platform that was especially designed at the start of the course. The lecture material was divided into four course modules that were built around chapters and corresponded to the different topic areas that the course covered. Each module contained a number of units, which contained the technical content of the module. Each unit had a voice-annotated PowerPoint presentation that took 15 to 30 minutes to view and the PowerPoint slides appeared in the browser. Each lecture was also subdivided into modular units that could be nonlinearly navigated using a menu of topics. The viewing schedule was designed to specify what units were to be viewed each week. However, it was up to the students to decide the exact time and day when they viewed the lectures. At times, guidelines had to be provided so that some students did not stay too far behind.

After the COVID-19 pandemic began, hyperlinks to multiple sites were added for each module to provide supplemental readings for those students who needed additional readings. However, those readings were not mandatory, but they were helpful as sometimes they provided information on how to solve specific problem-based assignments. Students could integrate web resources with the lecture, discussion, readings, and assignments. Frequently asked questions as well as quizzes on each course unit offered students direction on how to best utilize their time while studying for the tests. Another valuable part of the D2L package was the electronic gradebook. Students could view quiz and exam grades via D2L. The grades were immediately available to the students after completion of a multiple-choice exam or quiz. The electronic gradebook solved many problems associated with anonymous grade posting since the login was password protected and enabled easy access to grades. Students overwhelmingly appreciated the prompt feedback.

\section{On-line Submission of Student Assignments}

Students submitted assignments using the D2L email-drop feature. Homework served as an important measure of student progress. There were four individual problem-based assignments prior to the pandemic which had to be completed by the individual student. After the Covid-10 pandemic begin, the instructors adopted group assignments to allow students to collaborate and learn from each other. This also eliminated stress and uncertain environment caused by the remote learning which sometimes made students feel isolated. For each homework assignment the best two or three submissions were published on the bulletin board and served as reference for future work. This posting process also provided an 
added incentive for students to provide quality work. The questions for the homework were posted on the bulletin board at a predetermined time stated in a class syllabus. Answers were submitted to the instructor via course email. The format of the work was flexible, but the use of regular text documents and various word processing systems were accepted.

\section{Bulletin Board Discussions}

The "bulletin board" through D2L e-mail was held together with the virtual classroom whenever students were not actively engaged in real-time discussions like the chat room. It provided a forum for long running discussion on all class-related topics. The bulletin board space was divided into the following topic areas: MAIN - general discussion and class announcements; HELP - questions regarding the use of D2L tools and computers; HOMEWORK - questions regarding assignments; and MODULE 1-4 - questions specifically related to the content in any of the four modules as well as the relevant chat sessions. The effectiveness of instructor communication increased with use of the announcement feature that alerted students to the posting of new resource materials or a current event or issue related to the course. Students were also reminded about deadlines and important dates relevant to their work.

\section{Chat Sessions}

The chat sessions provided students with a real-time question-and-answer session for lecture related material. Each chat lasted 60 minutes and was moderated by a team of students to keep the discussion focused. Given the relatively short period of time, students were encouraged to post follow-up questions or issues and concerns not directly related to the lectures on the bulletin board. Chat sessions were coordinated with the lecture schedule and typically focused on no more than one or two units (or chapters). Before each chat session, the student moderators posted the discussion topics on the bulletin board so students could prepare in advance. Chat sessions were scripted and posted by each on the bulletin board.

\section{D2L Testing}

Examination using D2L has several advantages over traditional paper-and-pencil tests. First, this type of testing provides enhanced control in presenting item displays and information, allow greater standardization, and an increase the variety of testing forms. D2L tests also reduce testing time and measurement error and provide improved reporting due to immediate test scoring and feedback. Our tests nearly eliminated error in deriving scores, reduced scoring time by up to $70-80 \%$, provided a simple mechanism for storing and retrieving information, and provided immediate feedback to the student. We used primarily multiple-choice question format, however $75 \%$ of questions were problem-based. Students had to solve problems and provide a correct answer from "a" to "e" using multiple choice format.

\section{Managing Education in an Age of COVID-19 Uncertainty}

During the COVID-19 crisis, everyone involved in education - students, teachers, and administrators - has demonstrated concern for maintaining some form of educational rigor and academic standards expected for accreditation and educational integrity. While the public's focus is often on the role of the teacher, the fact is that teachers are most often engaged in background dialogue with their immediate school administrators and managers, while trying to determine what can and cannot be done in a remote learning environment. At USCGA, the decision to use specific software, including Microsoft Teams and D2L, was made by school administration working closely with our Information Technology department. Some decisions involved dealing with existing contracts as the pandemic set in and resourcing enhanced versions of existing technologies.

As elsewhere, all Coast Guard Academy faculty were suddenly faced with the need to teach remotely; flexibility and innovation were encouraged by the Academic Dean and Department Heads. Most faculty, responded very effectively to this new pedagogical reality, despite the fact that most Coast Guard Academy faculty had little to no experience teaching 
on remote software platforms; certainly it has never been part of the pedagogical tradition of military academies, where the effectiveness of small-sized classrooms is consistently emphasized and maintained. Due to that long-standing tradition of face-to-face pedagogy, Academy's administrators, unfamiliar with those platforms themselves, were suddenly responsible for the management of remotely taught programs.

In the first few months of the COVID-19 crisis it was estimated that over $90 \%$ of teachers at all levels of education, from elementary to university, had no experience with remote teaching methods or technologies; for certain, the vast majority readily expressed some concern, to include being uncertain (81\%), anxious (75\%), and overwhelmed (74\%) (Schaffhausen, 2020; Ferlazzo, 2020). While simultaneously stating that they felt "capable" of completing the task, most teachers readily admitted that they felt the need to reduce student expectations in their overall effort to complete their courses and to generally wrap-up the spring semester (Lederman, 2020). But for teachers and students alike, there was really no other option, leaving all involved with rather dramatic adjustments to daily routines. Beyond the steep learning curve for most, many teachers also wondered how to find a proper balance between pressing students to learn more material and paying attention to students' overall well-being; of course, as the COVID crisis continues, this concern remains. Accordingly, for school administrators in charge of managing new remote-based learning environments, gauging faculty comfort and engagement with these sudden changes was part of the challenge.

\section{Diverse Needs among Academic Programs}

It was immediately apparent to the Coast Guard Academy's school administrators that remote learning meant different things to different people and that not all faculty were on board with the idea of full conversion. Initially, there was some resistance to having all courses taught remotely; some seemed amenable, while others believed some form of "hybrid" arrangement would be necessary. Most doubts were raised by senior faculty who had been teaching face-to-face for a number of years. There also were particular challenges in STEM-related courses that required hands-on labs. Without doubt, all concerns were sincerely based on maintaining academic effectiveness and rigor. Ultimately faced with no real option but to somehow complete the spring 2020 semester remotely, there undoubtedly remained misgivings among many faculty members. Many understandably sought guidelines, which management also felt pressure to establish as the semester progressed. Ultimately, anxious for answers as to how best to promote the most effective and safe teaching environment during the pandemic, most continued to rely on dialogues among faculty within individual departments and readily consulted the internet for the latest information.

During Spring 2020 school administrators established a Remote Learning Task Force (RLTF) that included, among others, the Associate Dean for Academic Affairs, faculty from various programs delivering courses for academic credit, and IS staff (the USCGA information technology division). This task force was designed to share best practices in remote learning at USCGA and across higher education and to ensure that faculty and staff were equipped with the necessary tools and training to support their chosen style of remote delivery. RLTF information is posted on Teams, accessible to all faculty, and is regularly updated. Members of the RLTF presented various remote technologies and applications during a faculty in-service day.

The RLTF also gathers concerns and questions from the faculty to resolve any impediments to effective remote delivery. One evident concern was the danger of students copying each other's work, which resulted in this suggestion for a remote class "Honor Statement", by the Academy's math instructors as well as faculty in other disciplines. Another challenge that is ongoing is to maintain sufficient bandwidth and internet support to enable synchronous learning and other virtual activities needed during the pandemic. The information technology leaders have worked to upgrade hardware, software, email and internet capability as the entire 1100-person cadet corps, hundreds of Officer Candidates, faculty and staff would be relying on virtual options.

Honor Statement: The remote learning environment has provided many challenges and opportunities. One of those opportunities is for you to practice your personal honor and integrity with less supervision and help others to do the same. For each graded assessment that does not allow collaboration or consultation, you will be asked to respond to a statement indicating that you have not accessed any information or resource that is not expressly permitted on the assignment and that the work you are submitting reflects your own 
understanding of the material. Please carefully review the collaboration policy on all assignments and ask your instructor if you have any questions so that you can confidently follow the policy and proudly respond to the statement.

As the fall 2020 semester progressed, faculty were also encouraged to use other software packages, such as Camtasia, a tool for recording and sharing videos. In reality, the management model gradually merged into one of "collaborative management," based largely on goodwill of faculty and administration, always maintaining a free flow of dialogue on remote learning and pedagogical methods. Other important RLTF items have included: information on both Microsoft Teams and D2L training, the formulation of new policies regarding the recording of classroom discussions, and the maintenance of existing policies, to include inclusion and diversity. That dialogue continues.

\section{The Importance of Clear Guidance for School Administrators}

Due to uncertainty and difficulties in adjusting to the COVID-19 outbreak on short notice, school administrators understandably sought out clear guidance from local, state, and federal government authorities, but guidance has been dynamic, often vague, and completely lacking in some aspects. Amidst the growing anxiety of parents, students and faculty, school administrators (at all educational levels) were suddenly faced with the challenge of providing answers, suggesting solutions, and assuring that the infrastructure for remote learning was effective and properly funded. In the Academy's case, as discussed earlier, the required software support was in place. Faculty were usually required to learn Teams on the fly and determine other forms of pedagogical effectiveness as the spring 2020 semester came to an end. Along the way, all school administration meetings and search committees, for both faculty and staff, were suddenly run entirely on Microsoft Teams. Many involved would readily share that, in retrospect, they initially experienced a few hiccups along the way, as faculty and staff adjusted to the new Teams-oriented flows of communication.

Moreover, amidst pedagogical concerns and quick adjustments to Teams and other facilitating remote teaching software, schools around the country were adjusting their existing grading schemes. Some adopted Pass/Fail and other alternative grading options, while others maintained what they had used in the past. After much discussion, the Academy's administration made the decision to eliminate $\mathrm{H}$ grades (a grade normally awarded to top students in a class that carries a 4.0), minus grades, and D or F grades for the Spring 2020 semester. It was an attempt to mitigate a precipitous drop in GPA because the adjustment to remote learning would be difficult for some. Students who would normally receive a low grade would have a chance to retake the course or make up work and replace a placeholder $\mathrm{D}$ or $\mathrm{F}$ grade. Indeed, the strong views of individuals can be one of most significant ongoing challenges for school administrators in the post-COVID environments.

Another challenge at the USCGA involves decisions on how to balance delivery modes for academic, military, and athletic/health and fitness activities that are all part of developing well rounded officers for the Coast Guard. There have already been two interdivisional task forces to develop courses of action (COAs) for summer 2020 and the 2020-2021 academic year. At the end of the day, these COAs are suggestions and decisions must be made by Senior Leadership at the Academy and at Coast Guard Headquarters. These factors pose unique challenges to moving forward with decisions on academic delivery policy while also needing to ensure the health and resiliency of the faculty, staff, and cadets.

Throughout the COVID crisis, school administrators have also hoped for more specific educational guidance from officials within their own organization, home state, the CDC, the White House, and/or the US Department of Education but, for many reasons, responses have varied significantly; in fact, many - following the lead of the Trump Administration remain leery of federal government overreach and continue to believe that the best policy responses will come from more localized decision-makers that are best informed about local capabilities and conditions. For its part, the US Department of Education has scarcely addressed the resource questions and options surrounding remote learning, specifically, presumably falling in-line with the post-COVID White House push for re-opening all public schools in fall 2020. In August 2020, the only remote learning policy concerns expressed by the US Department of Education, under "Remote Learning: Resources for Educators, Administrators and Related Service Providers," are: 1) Protecting Student Privacy (FERPA) and 2) "U.S. Immigration and Customs Enforcement (ICE) issued guidance on Coronavirus Disease 2019 (COVID-19) and Potential Procedural Adaptations for F and M Nonimmigrant 
Students. (March 9, 2020).."1 Rather than take its own stance, the U.S. Department of Education's Institute of Education Sciences funds a network of ten Regional Educational Laboratories (RELs) that provide a hodge-podge of "best practices" on remote learning, based on "scientific evidence." Real "guidance" on pressing pedagogy concerns, therefore, is only provided at the state level and there too there regularly emerges a pattern of kicking responsibility for guidance between the state's departments of education and public health, with media coverage centering on the statements of the state governor.

At even lower levels of authority, there still remains more confusion than clarity; whether it is due to bureaucratic inertia or cautiousness, many state and town officials, as well as school principals and deans, have been frustratingly slow at providing clear guidance for teachers and parents alike. Like all of us, education officials follow the latest available data and policy information, but they also know that some advocate a return to in-person schooling, while others argue remote approaches are necessary, if only in the short-term. Parents and teachers, in particular, have strong points of view that only heighten the challenge of administrators to make the best official decisions. And of course, even as officials at all levels contemplate the best policy decisions and only occasionally take a stance, not everyone has the time or inclination to peruse the "daily updates" on COVID or other official policy statements. People are anxious in many ways and part of COVID-fatigue is just trying to keep track of where things stand in terms of openings or closings, which "phase" one's state is in, and what that means. Like everyone, amidst educational policy uncertainty and awareness - not to mention public divisiveness and growing angst over maintaining family incomes and paying bills - teachers have nevertheless been asked to adjust to our new COVID realities, somehow some way.

At the start of the fall 2020 semester, the Coast Guard Academy's IT department initially faced challenges due to heightened server demands with so many classes being taught simultaneously on Teams; the solution, in part to expand bandwidth, was immediately addressed. Importantly, throughout the momentary problems with administering Teams, Academy administrators and IT worked closely to inform all faculty of the status of circumstances. Once the COVID-19 pandemic shut down the face-to-face meetings and classroom instruction, the Academy administration had to provide necessary technical support and all other support as required on the individual department basis. Academic division worked very closely with the Information Technology personal for one week (during spring break) to move entire academic program into the distance learning. The task was not easy as some faculty members had never had any experience with the distance education and the Academy was not ready to accommodate distance learning across entire curriculum. The first step was to increase network and storage space for both the students and the faculty. Next steps involved upgrading and downloading programs on faculty and students' computers to accommodate distance learning followed by the faculty preparing their teaching materials for distance (remote) teaching. Without full support of the administration and Information Technology department, distance education will be infeasible, or it will provide poorly designed and delivered coursework.

\section{Lessons Learned}

Building and maintaining a virtual course can be time consuming. While many students are somewhat reluctant to embrace the technology at the beginning of a semester, almost all of them felt that the extensive use of the technology was extremely useful and worked well during remote course delivery. Tools like Microsoft-teams and D2L allowed instructors to add some level of interactivity and monitoring students' progress in the class and concentrate on these areas that require improvement. This type of progress checking can lead to more specific and in-depth questions and more meaningful discussion during the chat rooms and an individual advising.

The use of computer-based technology enhances students' collaboration and cooperation. Students were able to work with one another more often because of enhanced communication. Barriers of time, place, and distance between and among students are more easily overcome or eliminated. Microsoft-teams and D2L also allowed students to work together with simulations and "real-life" projects. Learning activities become increasingly real. Not only can instructors notify students of their homework or exam marks outside of class time, but instructional time is also saved because it was not used to collect and redistribute assignments. Course materials that were posted not only delivered course content and online 
quizzes and examinations but provided students with immediate feedback on their performance. Remote and technology instructional can improve student learning by helping students use their time more efficiently. Students can learn at their own pace at different times of day.

Much of the success of distance or virtual education rests on encouraging an active role for learners where students must learn to rely on themselves and master the technology necessary to thrive. Moreover, technological pressures call for providing education at technological level that is responsive to students' needs and more concerned about how well students are prepared to assume future societal roles when learning environment is impeded. During Covid-19 pandemic, the academic faculty members have felt the pressure to lecture less, to make learning environments more interactive, to integrate technology into the learning experience, and to use collaborative learning strategies when appropriate. The pedagogical approaches applied in distance learning development during COVID-19 pandemic recognize that students will be expected to show the level of independence and self-direction in the learning process. Therefore, from a perspective of the instructor, it became important to view the instructor's role as making a shift toward greater student participation and ownership of their own learning.

Used in conjunction with active or collaborative learning teaching strategies, the traditional lecture can be an effective way to achieve instructional goals. The advantages of the lecture approach are that it provides a way to communicate a large amount of information to many listeners, maximizes instructor control and is non-threatening to students. The disadvantages are that lecturing minimizes feedback from students, assumes an unrealistic level of student understanding and comprehension, and often disengages students from the learning process causing information to be quickly forgotten. In distance or virtual education, lectures are strongly recommended to be utilized as a chief platform of information distribution. While lecturing, the instructor should focus on the topic (less is better than more), organize points for clarity, select and use proper examples or illustrations. Presetting several sides of an issue and be sensitive to other perspectives are extremely successful elements of lectures in remote environment. Being enthusiastic and aware of own audience are also very critical elements for the success in lecturing.

Virtual or distance learning instruction should focus on capabilities for learners' collaboration and independence. Through the use of the Internet and the other components of distance education technology, the instructors are able to promote learner-centered instruction while utilizing participation, task performance and collaboration. Much of the success of distance or virtual education rests on encouraging an active role for learners where students must learn to rely on themselves and access to and master in the use of technology and all other coursework materials prepared by the instructor.

\section{The Course Evaluation}

The course evaluation indicated that several highly rated components of the course might be attributed to the use of technology, course organization, and enhanced courseware. For example, the instructor-student communication, organization of the course, material presentation and availability, course clarity, and timelines of the course content were highly ranked. The remote portion of the course was also highly rated as encouraging students to learn more about the course content. All of these findings indicate that the instructor's goals of fostering critical thinking as well as motivating students for lifelong learning about the content were met.

We have also collected a course evaluation to ensure that the best techniques used in the course will be utilized. Some of the students' comments are provided in Table 2.

Table 2. Selected Students' Comments Regarding Economics Course Delivered in Online Environment.

\footnotetext{
"The course moved quickly from classroom-based instruction into remote environment but its well-structured delivery from the very beginning allowed our instructors to provide minor changes that work better in the remote environment."
}

"D2L testing provided multiple choice testing but all questions were based on our problem- 
solving we had to work on during our assignments and provided via Power point Lecture Presentations that we had to learn on our own. However, instructor was available to an interactive learning."

"Technical support was good, online assignment submission allowed more flexibility in timing, and the instructor was very helpful as were able to learn on our own pace."

"The course would be more difficult, but it occurred to be more enjoyable than expected as instructor used variety of teaching tools."

"Remote learning was challenging but I learned a lot because of course materials available and how the course was set up with possible video-chatting and conferencing as well as welldesigned group assignments that allowed more interaction and confidence as students were able to learn from each other."

"If I had to take this course again, I would recommend the use of (student) own pace of learning, bulletin board discussion and multiple approaches of taking quizzes that allowed us to learn the material. Practice made me more learn as I was able to apply and analyze."

Based on our experiences with the computer-based technology courseware the following conclusions can be made:

1. Effective use of computer-based technology requires significant time and commitment to instructor training to build and deliver efficient online course.

2. Preparation and implementation of a remote- and computer-based course require the instructor's commitment to continued training in instructional strategies for remote or webenhanced courses. The technical training is critical to the implementation of web or computer-enhanced courses.

3. Students must receive ongoing training related to courseware and other support functions so that they can efficiently utilize the materials provided via remote courseware.

4. Student expectations for access to the instructor and support for quantity and quality of educational materials increase with the use of remote or web-enhanced courses.

5. Institutional (or administrative) support for faculty, staff, and students is essential for successful online learning.

6. Technical support is necessary and must be integrated with changes in instructional methods and course design.

7. Timeliness of content is immediate since access to the Internet and use of multiple web sites and course tools are available via D2L.

8. The use of computer and web tools enables students to develop problem skills as well as critical thinking skills for professional development.

9. Computer based instruction increased and improved access to course materials and email communication between the instructor and students. This improved communication helped reduce the social and educational isolation often experienced in large enrollment courses as well as eliminated stress caused by an urgent to the remote environment.

\section{Conclusions}

Computer-based technology instruction has provided new opportunities for teaching and learning. The numerous tools provided a dynamic environment where distributed information was accessed without constraints of geographic location or time. Computer-based instruction enables self-directed and self-paced instruction. Students can set their own pace and repeat sections or move around within the tutorial until they feel they have assimilated the materials. Self-assessment tests give students further control over the learning process by providing them with immediate feedback on their progress. Self-assessments also inform the student of topics in which they should seek additional assistance from the instructor.

Computer-based technology and teaching promote active learning by emphasizing activities of exploration and discovery and by making it easy and effective for students to create their own learning platforms by using numerous materials. It emphasizes collaborative learning by allowing the students to interact with the instructor and other students via e-mail, on-line chat, and group discussions. It is easy to "log" activity on a website allowing the instructor to monitor learning and determine the effectiveness of the instruction provided. 
Faculty can assume the roles of counselor, guide, and mentor as never before. With new computer-based technology courses, they can spend more time planning and facilitating learning and developing higher order skills and less time presenting content.

With the technological capabilities available for the course delivery, students can take more responsibility for their own learning. They can assess information from more resources than just a single instructor or a single textbook, and they can collaborate with other students within their class, leading to increased levels of interactivity. While many students are somewhat reluctant to embrace the technology at the beginning of a semester, almost all of the students eventually felt that the extensive use of the technology was extremely useful.

Computer-based technology instruction can improve the quality of the educational experience for most students. Faculty considering remote courseware should be aware of the additional time needed for planning, training, and instructor accessibility. The computerbased technology tools provide browser-based administration and design of online course presentation and allow the instructor's full management of the entire course. On-line instruction can combine features of communication, passive and active learning, and independent and group experiences. The development of a teaching-learning system via the use of Microsoft Teams and D2L represents a considerable investment in time and effort as well as in elimination of the unnecessary stress for students who participate in learning. Nevertheless, with the proper systems in place, including adequate technology and support, sufficient funds, and the cooperation of educational administrators, students and the publishers can augment current educational systems in remarkable ways.

\section{Footnotes}

${ }^{1}$ https://www.ed.gov/coronavirus/remote-learning (Retrieved August 5, 2020).

${ }^{2}$ https://ies.ed.gov/ncee/edlabs/projects/covid-19/ (Retrieved August 10, 2020).

\section{References}

Angiello, R. (2010). Study looks at online learning vs. traditional instruction. Education Digest, 76(2), 56-59.

Angelino, L. M., \& Natvig, D. (2010). A conceptual model for engagement of the online learner. Journal of Educators Online, 6(1), 1-19.

Alves, P., Miranda, L., \& Morais, C. (2014). Open Educational Resources: Higher Education Students' Knowledge and use. In Rikke Ørngreen \& Karin Tweddell Levinsen (Eds.), Proceedings of the $13^{\text {th }}$ European Conference on e-learnig ECEL 2014. Reading, UK: Academic Conferences and Publishing International Limited. $11-18$

Beck, V. S. (2019). Comparing online and face-to face teaching and learning. Journal on Excellence in College Teaching, 21(3), 95-108.

Burdea, G., and Coiffet, P. (1994). Virtual reality technology. New York: Wiley.

Curtis, D. D., and Lawson, M. J. (2001). Exploring collaborative online learning. Journal of Asynchronous Learning Networks, 5(1), 21-34.

Ferlazzo, L. (2020).“Six weeks into remote teaching still learning," EdWeek.org, May 1, 2020, Retrieved from: https://blogs.edweek.org/teachers/classroom_qa_with_larry_ferlazzo/2020/05/six_weeks_into_remote_teachin g_still_learning.html

Fish, W. W., and Wickersham, L. E. (2019). Best practices for online instructors: Reminders. Quarterly Review of Distance Education, 10(3), 279-284.

Guthrie, K. L., and McCracken, H. (2010). Reflective pedagogy: Making meaning in experiential based online courses. Journal of Educators Online, 7(2), 1-21.

Juwah, C. (2006). Interactions in online peer learning. In R.C. Sharma and. C. Juwah (Eds.) Interactions in online education. Implications for theory and practice, New York: Lawrence Erlbaum., pp. 171-190.

Kearsley, G. (2000). Online education: Learning and teaching in cyberspace. Belmont, CA: Wadsworth.

Lederman, D. (2020). "How teaching changed in the (forced) shift to remote learning," InsideHigherEd, April 23, 2020, Retrived from: https://www.insidehighered.com/digital-learning/article/2020/04/22/how-professorschanged-their-teaching-springs-shift-remote 
Schaffhausen, D. (2000). "Educators Feeling Stressed, Anxious, Overwhelmed and Capable,"The Journal Transforming Education Through Technology, June 2, 2020, Retrieved from:: https://thejournal.com/articles/2020/06/02/survey-teachers-feeling-stressed-anxious-overwhelmed-andcapable.aspx

Trajkovic, D., Davcev, G. Kimovski, and Z. Petanceska, (2000). "Web - Based Virtual Classroom", In Proc. Of the TOOLS 34, Santa Barbara, California, USA, July 30-August 4. 